\title{
Central Functions of Glucagon-like Peptide-1: Roles in Energy Regulation and Neuroprotection
}

\author{
Rachel T McGrath ${ }^{1,2^{*}}$, Sarah J Glastras ${ }^{1,2}$, Samantha L Hocking ${ }^{1,2}$, lona Tjoeng ${ }^{3}$, Martin Krause ${ }^{2,3}$ and Gregory R Fulcher $^{1,2}$ \\ ${ }^{1}$ Department of Diabetes, Endocrinology and Metabolism, Royal North Shore Hospital, St Leonards, NSW 2065, Australia \\ ${ }^{2}$ University of Sydney, Northern Clinical School, St Leonards, NSW 2065, Australia \\ ${ }^{3}$ Department of Neurology, Royal North Shore Hospital, St Leonards, NSW 2065, Australia
}

*Corresponding author: Rachel McGrath, Department of Diabetes, Endocrinology \& Metabolism, Level 3, Acute Services Building, Royal North Shore Hospital, St Leonards, Sydney, NSW 2065, Australia, Tel: +61 (2) 9463 1470; Fax: +61 (2) 9463 1045; Email: Rachel.McGrath@health.nsw.gov.au

Rec date: Sept 14, 2015, Acc date: Feb 17, 2015, Pub date: Feb 25, 2015

Copyright: (C) 2015 McGrath R, et al. This is an open-access article distributed under the terms of the Creative Commons Attribution License, which permits unrestricted use, distribution, and reproduction in any medium, provided the original author and source are credited.

\begin{abstract}
The identification of the glucagon-like peptide-1 receptor in the central nervous system has led to an array of studies exploring the functions of central GLP-1 signalling. Originally identified as a gastrointestinal incretin hormone responsible for the potentiation of insulin secretion following ingestion of nutrients, the role of GLP-1 has been expanded to include specific neural activities. Two distinct actions of GLP-1 receptor activation in the brain have been identified, namely the regulation of appetite via promotion of satiety, as well as anti-inflammatory and antiapoptotic activity to promote neuronal cell survival. Both of these features are now being exploited clinically, with GLP-1 receptor agonists, initially designed and marketed for the treatment of hyperglycaemia in type 2 diabetes, now being directed towards use in obesity and as potential neuroprotective agents. This review gives a summary of the functional role of GLP-1 in the central nervous system, in terms of promoting satiety, modulating food intake and aiding in the regulation of peripheral glycaemia. In addition, the molecular mechanisms underpinning the beneficial effects of central GLP-1 receptor agonist therapy in protecting against neuronal cell inflammation and death, including neurodegenerative processes, are described.
\end{abstract}

Keywords: Glucagon-like peptide-1; Central nervous system; Glucose metabolism; Satiety; Neuroprotection

\section{Introduction}

\section{Glucagon-like Peptide-1}

Glucagon-like peptide-1 (GLP-1) is a peptide hormone secreted from specific populations of cells in both the distal gut and central nervous system (CNS). In response to nutrient intake, GLP-1 exerts its insulinotropic activity via direct stimulation of pancreatic $\beta$-cells to potentiate insulin secretion in a glucose-dependent manner [1]. Thus, the principal metabolic function of GLP-1 is that of an incretin hormone. GLP-1 further lowers blood glucose levels by slowing gastric emptying, thereby reducing postprandial hyperglycaemia. In addition, GLP-1 participates in the gut-to-brain axis by transmitting nutritional signals to the CNS, resulting in increased satiety [2].

The GLP-1 peptide is produced through posttranslational processing of proglucagon in the intestinal L-cells and preproglucagon neurons in the hindbrain [3]. Native GLP-1 is 37 amino acids in length and is proteolysed by prohormone convertase $1 / 3$ to give rise to the major active circulating peptide; GLP-1(7-36)-amide [4]. This peptide engages and activates the GLP-1R on the surface of pancreatic $\beta$-cells when plasma glucose levels $\geq 5 \mathrm{mMol} / \mathrm{L}$, resulting in a rise in intracellular $\mathrm{Ca} 2+$ and consequent secretion of insulin. GLP-1 mediated signalling also reduces the expression of pro-inflammatory and pro-apoptotic mediators, leading to enhanced pancreatic $\beta$-cell viability $[5,6]$.
Regulation of endogenous GLP-1 activity occurs through rapid proteolytic inactivation in the circulation by dipeptidyl peptidase- 4 (DPP-4), such that GLP-1 has a half-life of approximately 3 minutes. While the short half-life of GLP-1 limits the therapeutic utility of the native protein as a diabetes treatment, the development of degradation resistant forms of GLP-1 and inhibitors of DPP-4 (DPP-4i) has proved an important therapeutic advance in the management of type 2 diabetes [7]. Furthermore, due to the glucose-dependent nature of incretin-mediated insulin release, GLP-1 receptor agonists and DPP-4i are associated with a minimal risk of inducing hypoglycaemia [8].

The GLP-1 receptor (GLP-1R) has been localised in tissues outside the pancreas, including the heart, kidney and brain [9]. It is widely distributed throughout the central nervous system (CNS), with expression in the thalamus, hypothalamus, hippocampal region, cerebellum, cortex and brain stem [10]. Interestingly, GLP-1 has also been identified as a neuropeptide, and is produced by preproglucagon neurons of the nucleus of the solitary tract (NTS) located in the caudal brainstem [11,12]. Furthermore, GLP-1 positive cells have been identified in the hippocampus and cortex in rodents and GLP-1 is secreted from microglial cells via a cyclic AMP (cAMP) dependent pathway [13]. It has also been observed that the GLP-1 peptide can cross the blood brain barrier [14].

The pleiotropic actions of GLP-1 to preserve $\beta$-cell function and reduce inflammation have led to the hypothesis that GLP-1 receptor activation could also have beneficial effects in the CNS. In addition to the regulation of satiety following a meal, experimental data also suggest an important role of GLP-1 in neuroprotection. An overview of these data is provided below, with a focus on the effect of GLP-1 receptor activation in the modulation of food intake and glucose 
homeostasis, as well as the neuroprotective and anti-inflammatory properties of GLP-1 in ischaemic stroke and neurodegenerative disorders.

\section{Central Activity of Glucagon-Like Peptide-1}

\section{Regulation of food intake}

Ingestion of food leads to GLP-1 secretion from entero endocrine L-cells in the distal gut. As a consequence, insulin release from the pancreas is stimulated in a glucose-dependent fashion and satiety is increased through both central and peripheral effects [15]. There are several possible mechanisms through which GLP-1 modulates food intake. Firstly, GLP-1 transmits nutritional signals to the brain via activation of the enteric nervous system and/or vagus nerve in the gastrointestinal tract $[16,17]$. It has also been suggested that a small proportion of GLP-1 may escape degradation by DPP-4 and enter the systemic circulation to cross the blood brain barrier, where it may directly activate its receptor and increase satiety [18]. Moreover, food intake may lead to the release of GLP-1 from neurons in the nucleus of the solitary tract (NTS), and the activation the GLP-1R in the CNS [19]. GLP-1 additionally adds to the regulation of energy intake by decreasing gastrointestinal motility, thereby contributing to feelings of fullness [20].

In the absence of nutrient ingestion, central administration of GLP-1 limits food intake [18]. Intracerebro ventricular (ICV) injection of GLP-1 in rodents slowed gastric emptying, through non-adrenergic and non-cholinergic pathways [21]. The mechanisms through which this centrally mediated reduction in gastric motility occurs have not been completely elucidated, however a role for vagal afferent nerves has been proposed. Nutrient stimulated secretion of GLP-1 from the distal gut led to activation of hepatic vagal nerves [22], and the suppression of food intake mediated by peripherally administered GLP-1 was abolished in vagotomised individuals [23]. Targeted administration of GLP-1 receptor agonists in the hypothalamus and hindbrain diminished food intake, suggesting that both of these cerebral areas are important for GLP-1 mediated anorexia [24,25]. Furthermore, GLP-1 reactive nerve fibres extend from the NTS to the hypothalamus, a major centre in the brain for regulation of eating behaviour, and activation of hypothalamic GLP-1R inhibits feeding and promotes satiety $[19,26]$. In addition, ICV administration of the GLP-1 receptor agonist, exendin-4, gave rise to activation of neuropeptide $\mathrm{Y}$, neurotensin, ghrelin and proopiomelanocortin neurons in the hypothalamus, leading to upregulated expression of appetite-regulating neuropeptides [27]. More recently, it was found that nestin-Cre mediated site-specific knockdown of the GLP-1 receptor in the hypothalamus and brain stem rendered high-fat fed rodents resistant to reductions in body weight and food intake induced by the long-acting GLP-1 analogue, liraglutide [28].

Several of the cellular pathways through which GLP-1R activation in the CNS modulates appetite have been identified. GLP-1 stimulates signalling cascades downstream of cAMP and protein kinase A (PKA) in the NTS, resulting in inhibition of food intake [29]. In particular, hindbrain GLP-1R activation suppresses energy intake via a PKAmediated reduction in adenosine monophosphate protein kinase (AMPK) activity and concurrent upregulation of mitogen-activated protein kinase (MEK)/extracellular signal-related kinase-1/2 (ERK-1/2) pathways [24]. This has been proposed to ultimately lead to $\mathrm{Ca} 2+$-dependent depolarisation of GLP-1R expressing neurons, and long-term cAMP response element-binding protein (CREB)-mediated transcriptional changes in genes responsible for regulation of food intake [30]. Surprisingly, a role for the central cytokines interleukin- $1 \beta$ (IL-1 $\beta$ ) and IL- 6 was found in GLP-1 mediated suppression of food intake [31]. Ablation of IL-1 $\beta$ or IL- 6 activity through either receptor blockade or knock-out gave rise to a reduction in GLP-1 mediated anorexia and loss of body weight in mice.

In clinical studies, infusion of GLP-1 led to increased satiety and reduced energy intake in obese individuals and also in patients with type 2 diabetes [32,33]. Similarly, GLP-1 dose-dependently reduced nutrient intake in lean and overweight individuals [34]. Interestingly, functional magnetic resonance imaging (fMRI) of the brain has shown that infusion of GLP-1 attenuates blood-oxygen level dependent signal changes in fasted individuals who were presented with images of food [35]. Likewise, continuous administration of exenatide, a GLP-1 analogue, reduced food intake in obese men which correlated with enhanced hypothalamic activity, as measured by fMRI [36]. The favourable effects of GLP-1 on reducing appetite and food intake have been exploited in a recent clinical trial, where liraglutide therapy for 56 weeks resulted in clinically significant weight loss in non-diabetic obese individuals [37] With additional human studies underway $[38,39]$, it is highly likely that a new therapeutic indication for GLP-1 will be established in the coming years, to aid in the reduction of excess body weight in obese individuals through augmentation of central GLP-1R mediated appetite suppression.

\section{Glycaemic Control and Peripheral Glucose Homeostasis}

While the chief physiological function of GLP-1 is in the glucosedependent stimulation of insulin secretion to regulate systemic glycaemia, a glucose lowering effect of GLP-1 has also been recognised in the brain. In healthy male subjects administered glucose via IV infusion, GLP-1 leads to decreased glucose concentrations in all cerebral areas with an increase in glucose metabolism through enhanced hexokinase activity during hyperglycaemia [40]. Similarly, glucose transport across the blood brain barrier (BBB) is downregulated by GLP-1 in healthy individuals with normal blood glucose levels [41]. In the presence of hypoglycaemia, GLP-1 does not affect brain-glucose concentrations, nor does it influence glucose metabolism or transfer across the BBB [42].

A further role of central GLP-1 is to regulate peripheral glucose homeostasis (Figure 1). As evidenced in animal studies, stimulation of the GLP-1R in the CNS leads to increased insulin secretion and greater hepatic glycogen storage, during hyperglycaemia [43]. Interestingly, GLP-1 signalling in the CNS facilitates glucose-uptake into skeletal muscle in an insulin-dependent and non-insulin dependent manner, as seen in MIRKO mice, a muscle insulin receptor knock-out model. In another study, ICV administration of GLP-1 in rodents augmented glucose-dependent insulin release, and decreased glucose production in the liver [44]. Moreover, it was demonstrated that antagonism of arcuate GLP-1 receptors in the rat brain increased the magnitude of glycaemic excursion during a glucose tolerance test. GLP-1 regulates peripheral glucose levels via activation of the afferent nervous system, through slowed gastric emptying and a concomitant reduction in absorption of glucose into the bloodstream [45]. Furthermore, GLP-1 can promote enhanced energy expenditure, through CNS signalling pathways; ICV administration of GLP-1 gave rise to increased thermogenesis in brown adipose tissue of C57BL/6 mice, which the authors suggest contributes to the mechanisms by which GLP-1 regulates energy balance [46]. 


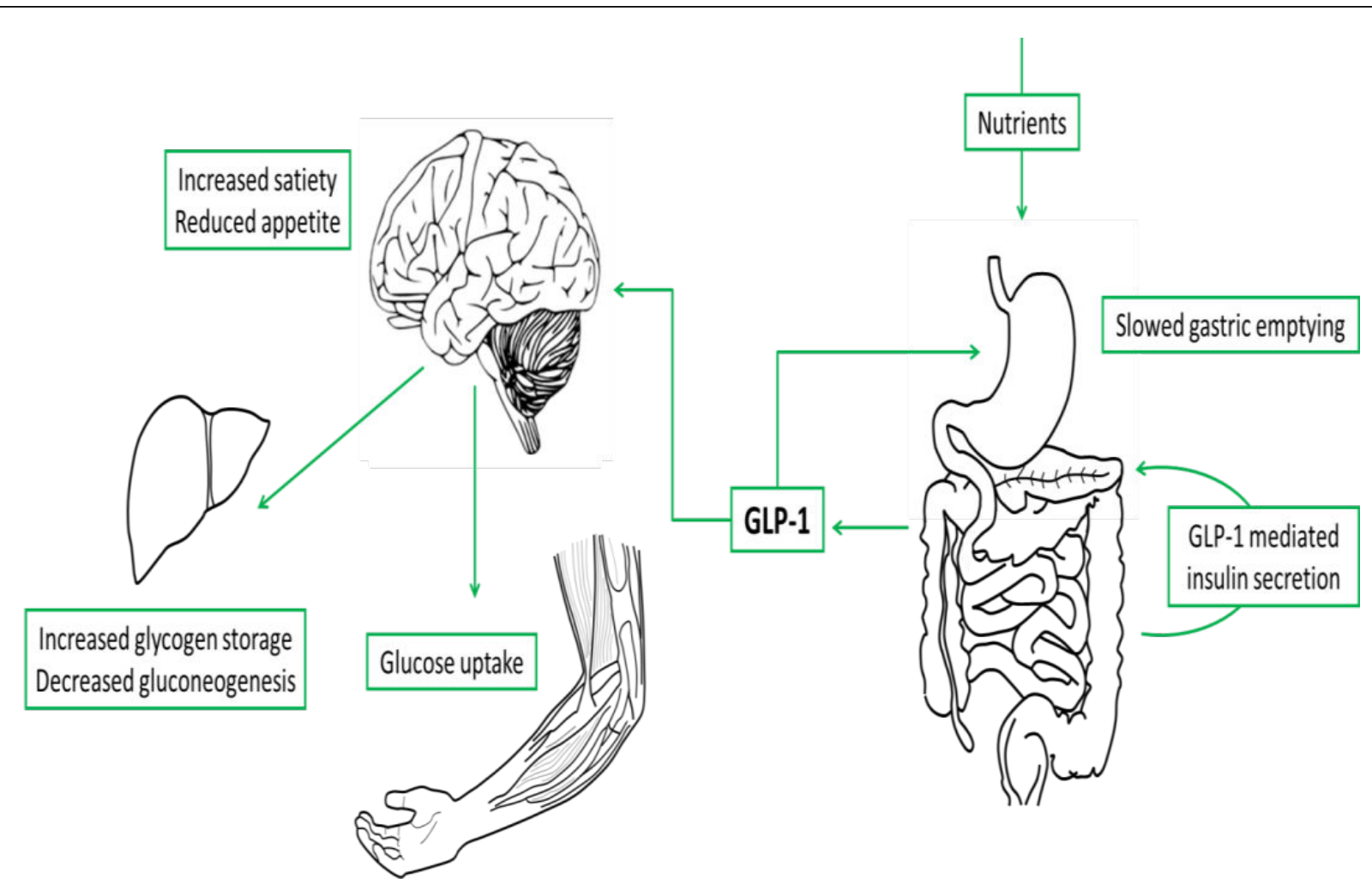

Figure 1: Functions of GLP-1 in the regulation of glycaemia. Upon ingestion of food, GLP-1 is secreted from the L cells in the lower gut and potentiates (glucose-dependent) insulin secretion from pancreatic $\beta$-cells, whilst also stimulating centrally mediated signals that give rise to a reduction in appetite, and peripheral uptake of glucose in both liver and muscle.

Sisley et al. recently observed that CNS expression of the GLP-1R is not necessary for peripheral glucose regulation, as administration of liraglutide reduced glucose excursions in the absence of neuronal GLP-1R [28]. This implies that pancreatic GLP-R activation is sufficient for the glucose lowering activity of GLP-1; however previous evidence suggests a direct role of central GLP-1R activation in the modulation of systemic glucose homeostasis [43,44]. Finally, administration of the GLP-1 receptor agonist liraglutide to patients with type 2 diabetes gave rise to a decrease in fasting endogenous glucose release due to a reduction in hepatic glycogenolysis, although the role of central GLP-1R signalling in this process is unclear [47].

\section{Glucagon-like Peptide-1 and Neuroprotection}

\section{Anti-inflammatory properties of GLP-1 in the brain}

The cytoprotective and anti-inflammatory effects of GLP-1 have been demonstrated in several cell types, including pancreatic islets and endothelial cells [48-50]. In addition, a recent study has shown that stimulation of the GLP-1 receptor reduces the inflammatory response in the kidneys of diabetic rodents, independent of GLP-1 bloodglucose lowering activity [51]. In each of these studies, improvements in cell viability and a concomitant reduction in the expression of proinflammatory adhesion molecules and cytokines was observed.

In vitro experiments initially revealed that GLP-1 exerts neuroprotective activity in neuronal cell culture, [52] promotes cell survival and proliferation, and prevents apoptosis and oxidative- stress-associated cell death in mammalian glial and hippocampal cells (Figure 2). The pathways involved in GLP-1 mediated neuronal cell proliferation are downstream of protein kinase $\mathrm{A}$ and phosphoinositide 3-kinase activity, and enhanced cell survival arises through modulation of apoptotic signal expression (decreased bax and caspase-3, and increased bcl-2; Figure 3) [53-56]. GLP-1 further regulates inflammatory cytokine expression in the brain; lipopolysaccharide (LPS) challenge in activated microglia and astrocytes gave rise to a significant increase in IL- $1 \beta$, and this increase was attenuated in the presence of GLP-1 [57]. This finding is in contrast to that observed by Shirazi and colleagues, who showed that GLP-1 promotes IL- $1 \beta$ expression in the brain, to reduce food intake and appetite. Thus, GLP-1 may differentially influence the expression of central cytokines, dependent on the initial stimulus or upon which signalling pathway is activated. More recently, it was found that the GLP-1 receptor agonist liraglutide enhanced cell viability and prevented cytotoxicity and apoptosis in human neuroblastoma cells exposed to methylglyoxal stress [58]. The mechanisms through which this increase in cell viability occurs include activation of the transcription factor p90RSK, which modulates the expression of genes associated with the cellular response to stress. 


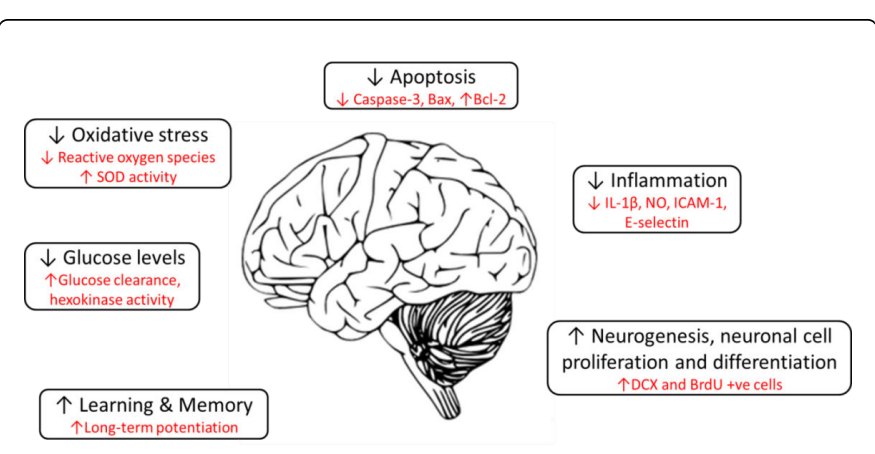

Figure 2: Glucagon-like peptide-1 activity in the brain gives rise to neuroprotection, through various molecular mechanisms. The mechanisms through which GLP-1 elicits a neuroprotective effect in the brain are outlined. General mechanisms are indicated in black, with specific molecular pathways in red. GLP-1 enhances neurogenesis, neuronal cell proliferation and differentiation, as evidenced by increases in the cell proliferation markers DCX and BrdU. Stimulation of the GLP-1 receptor prevents apoptosis, with a decrease in pro-apoptotic signalling molecules caspase-3 and bax, as well as greater levels of anti-apoptotic bcl-2 observed. Favourable effects on learning and memory are also seen, as reflected by enhancements in long-term potentiation, a marker of synaptic plasticity and a major mechanism underlying the processes of memory and learning in the brain. Oxidative stress is ameliorated through a reduction in reactive oxygen species. Finally, GLP-1 lowers blood glucose levels in the brain, preventing hyperglycaemia associated inflammation and cell death during ischaemia [40].

The role of GLP-1 in attenuating neuroinflammation has been also demonstrated using animal models. Both liraglutide and its metabolite GLP-1 (9-36) decreased the expression of pro-inflammatory markers such as ICAM-1 and E-selectin after intracerebral haemorrhage in mice [59]. Indeed, it was also found that liraglutide reduced the number of neutrophils in the perihaematoma region, further downregulating neuroinflammation. In addition, chronic irradiationinduced inflammation in rodent brains was ameliorated by treatment with GLP-1, with lower levels of markers such as interleukin-6 and nitrite observed [60,61]. GLP-1 receptor stimulation through treatment with the GLP-1 analogue exendin-4 minimised mild traumatic brain injury induced deficits in mice, again through reduction of oxidative stress associated inflammation [62]. This study demonstrated that administration of GLP-1 gave rise to increased levels of neuronal cell survival in response to challenge with the oxidative stress mediator hydrogen peroxide, and also protected cells against glutamate-induced toxicity.

Due to the modulatory effects of GLP-1 on neuroinflammation, a key process in the pathogenesis of neurodegenerative disorders and cerebral injury, it has been proposed that GLP-1 may be a viable treatment option for targeting inflammation in the brain, and as such, further clinical studies in this area are warranted

\section{GLP-1 and Ischaemic Stroke}

Diabetes is an established risk factor for the development of ischaemic events, such as stroke. Persistently high blood glucose after stroke correlates with larger infarct volume, and hyperglycaemia is an independent predictor for increased functional impairment, disability and mortality [63-66]. The mechanisms through which hyperglycaemia may exert a deleterious effect in ischaemic stroke include heightened lactic acidosis, enhanced production of free radicals, oxidative stress and augmentation of inflammation. As previously described, GLP-1 effectively lowers hyperglycaemia in the brain and furthermore, ameliorates oxidative stress and inflammation in preclinical models of brain injury and inflammatory challenge [40]. In addition, GLP-1 therapy resulted in favourable effects in a rodent model of ischaemic stroke and concomitant type 2 diabetes, with a dose-dependent reduction in hyperglycaemia, inflammation and neuronal tissue damage [67]. Treatment of mice with the DPP-4 inhibitor linagliptin significantly enhanced circulating levels of GLP-1, and lowered both fasting and fed blood glucose levels. Treated mice also showed a marked decrease in ischaemic brain damage [68].

In a recent clinical study, patients with acute ischaemic stroke were given subcutaneous exenatide for glycaemic control. It was observed that blood glucose levels were effectively regulated, with minimal incidence of hyperglycaemia and no symptomatic hypoglycaemia [69]. These promising preliminary results suggest that GLP-1 therapy may be a viable treatment option for individuals with hyperglycaemia in ischaemic stroke, with negligible glycaemic variability, and low risk of hypoglycaemia. This may lead to improved outcomes for patients with acute stroke, as hypoglycaemia has been associated with poorer outcomes and an increased risk of morbidity and mortality [70].

The mechanisms through which GLP-1 exerts its beneficial effects in stroke, in addition to glycaemic control, have been determined in a variety of preclinical models. Administration of exendin- 4 was shown to reduce brain damage and improve functional outcome in a transient middle cerebral artery occlusion stroke model, independent of its blood glucose lowering activity [71,72]. Likewise, treatment of rats with exendin-4 confers significant neurological protection following cerebral ischemia as a consequence of middle cerebral artery occlusion with a reduction in infarct size, oxidative stress levels and neurological deficit [73]. In particular, exendin- 4 was found to increase the levels of superoxide dismutase (SOD), an antioxidative enzyme that reduces the concentration of harmful superoxide within cells. More recently, GLP-1 treated rats showed an improvement in behavioural score and smaller infarct volumes after stroke [74]. A reduction in reactive oxygen metabolites and an increase in the levels of vascular endothelial growth factor (VEGF) were seen, reinforcing the premise that GLP-1 down-regulates oxidative stress and promotes oxygenation. It has also been observed that administration of exendin- 4 to rodents protects against ischaemia-induced activation of microglial cells, thereby preventing premature microglial cell death [75].

Interestingly, GLP-1 exerts cardioprotective activity in patients with myocardial infarction (MI) and ischaemic heart disease. In a small cohort of non-diabetic patients, treatment with GLP-1 led to an improvement in left ventricular function (LVF) and a reduction in ischaemic dysfunction after coronary balloon occlusion during percutaneous coronary intervention [76]. Infusion of GLP-1 to patients after acute MI enhanced LVF and increased recovery in the peri-infarct area, and exenatide was shown to improve myocardial salvage after ST-segment elevation MI [77,78]. Epidemiological data has further found that individuals taking exenatide had a lower incidence of cardiovascular disease, including stroke [79]. These results, taken together with the above animal data, suggest that GLP-1 therapy may lead to favourable outcomes after ischaemic injury, both in the heart and CNS. Indeed, GLP-1 may exert a dual protective effect in the ischaemic brain, in terms of preventing hyperglycaemia 
associated neurological damage, and directly ameliorating neuro inflammation and oxidative stress associated cell death.

\section{Protective Role of GLP-1 in Neurodegenerative Disorders}

The risk of developing neurodegenerative disorders such as dementia and Parkinson's disease is significantly increased in individuals with diabetes $[80,81]$. The pathogenesis of neurological impairment and injury in these disorders includes premature neuronal cell death, oxidative stress and neuro inflammation, processes that may be attenuated by GLP-1 signalling in the brain. Interestingly, GLP-1 receptor knockout mice demonstrated impaired learning, memory and cognitive ability, as well as a reduction in recovery after neurological insult, suggesting an intrinsic role for endogenous GLP-1 in maintaining normal brain activity $[82,83]$.

Pre-clinical models of neuro degeneration have been used to show that GLP-1 therapy is beneficial in preserving neurological function. In a mouse model of Alzheimer's disease, both short- and long-term administration of the GLP-1 receptor agonist, liraglutide, resulted in increased neuronal cell survival and proliferation, and enhanced neurogenesis [84]. Furthermore, several studies have demonstrated that GLP-1 preserves synaptic plasticity and further reduces the accumulation of the pathogenic $\beta$-amyloid protein in the brain of preclinical models of Alzheimer's disease [61,85]. Administration of GLP-1 dose-dependently conserved spatial memory in rats exposed to $\beta$-amyloid, by protecting hippocampal long-term potentiation between neurons. Similarly, GLP-1 was found to be protective against neuro degeneration in a Parkinson's disease model; administration of exendin- 4 reduced functional impairment and also increased the number of neuronal precursor cells, showing protection against loss of neurons $[86,87]$. Treatment with exendin-4 increased levels of LDOPA and tyrosine hydroxylase after challenge with 6-OHDA (a selective inducer of Parkinsonism), suggesting that GLP-1 can rescue dopaminergic neurons after damage has occurred. Finally, GLP-1 improves motor performance and extends survival in a murine model of Huntington's disease [88].

GLP-1 is currently being explored as a potential neuroprotective agent in patients with dementia and Parkinson's disease [89]. A recent pilot study investigated the effect of exenatide treatment in addition to regular therapy on neurological function in non-diabetic individuals with Parkinson's disease. Exenatide was well tolerated and patients in the treated group showed a significant reduction in disease progression and improvements in motor and cognitive skills [90]. Phase 1 studies have also been completed for a novel GLP-1 delivery system, where CellBeads ${ }^{\bullet}$ containing mesenchymal stem cells that overexpress GLP-1 are inserted directly at the site of injury in patients with haemorrhagic stroke, with the aim of eliciting GLP-1 mediated protection against neuronal cell damage [91]. Two further clinical trials have been described, where the effect of liraglutide on glucose metabolism and functional outcome in Alzheimer's disease, and in reducing reperfusion injury after acute stroke will be studied [92,93]. Moreover, GLP-1 has also been suggested as a prospective treatment option for the cognitive impairments observed in individuals with mood disorders [94].

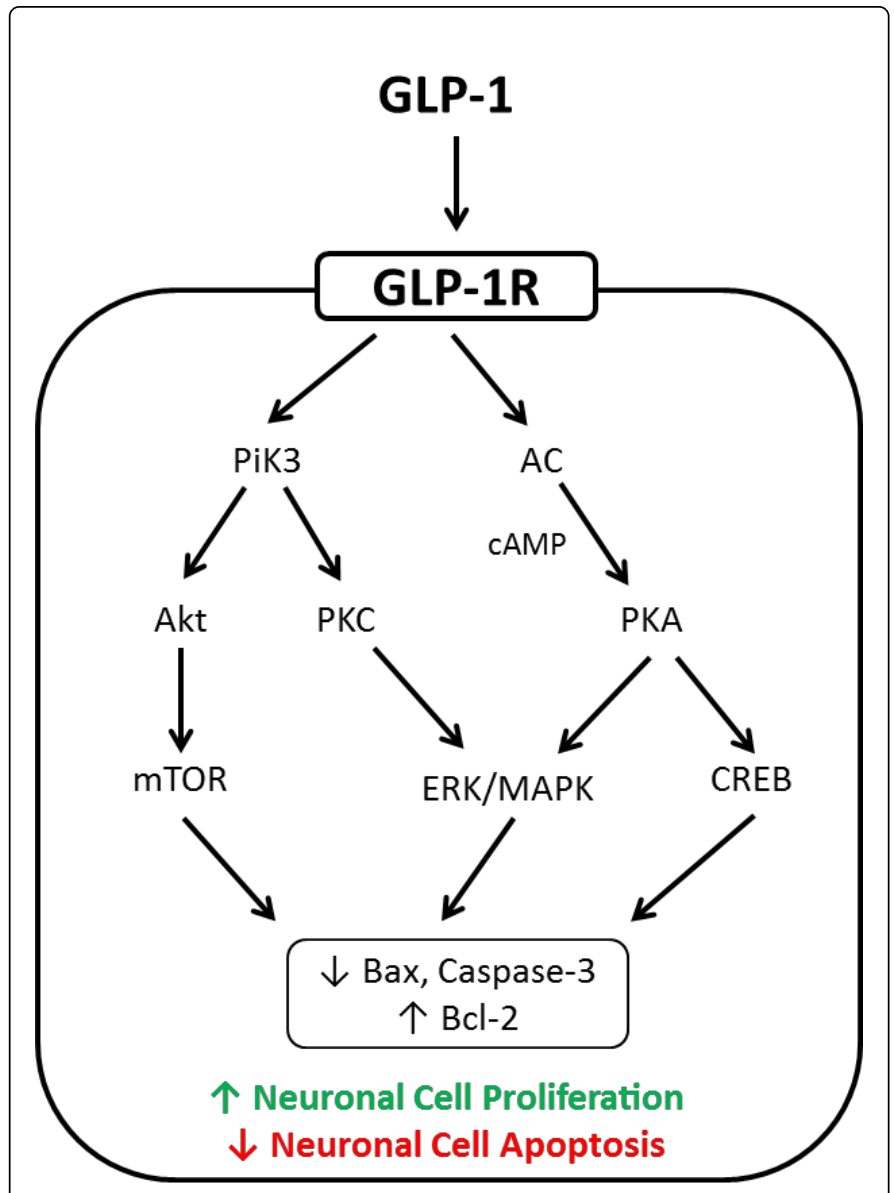

Figure 3: Summary of the principal signalling pathways through which glucagon-like peptide-1 receptor activation promotes neuronal cell survival. Stimulation of the GLP-1R on the surface of neuronal calls activates protective signalling pathways, downstream of phosphoinoside kinase 3 ( $\mathrm{PiK} 3$ ) and adenylate cyclase (AC) [63]. Activation of protein kinase A (PKA) leads to modulation of prosurvival gene expression via the extracellular signal-related kinase/ mitogen-activated protein kinase (ERK/MAPK) and cAMP response element-binding protein (CREB) pathways [52,56]. Similarly, protein kinase C (PKC) and Akt signal through ERK/ MAPK and mTOR (mammalian target of rapamycin), respectively, to promote neuronal cell proliferation and modulate levels of apoptotic gene expression (decreased Bax and Caspase-3; increased Bcl-2).

\section{Conclusions}

Characterisation of GLP-1R activation in the CNS, in both in-vitro and pre-clinical models has enabled an understanding of the dual regulatory activities of central GLP-1 signalling. First, GLP-1R activation leads to increased satiety and a reduction in food intake [95]. Second, GLP-1 signalling in the brain regulates peripheral glucose metabolism, through modulation of glucose uptake. Thus, GLP-1 has an important role in energy homeostasis; initially to regulate food intake limiting nutrient ingestion and further to influence how nutrient-derived energy is metabolised peripherally. 
Another consequence of central GLP-1R activation is in the protection of neuronal cells against damage and premature cell death. This neuroprotective activity of GLP-1 is achieved through ameliorating inflammation and oxidative stress, processes that occur in the brain after an ischaemic event and also during neurodegeneration. In addition, GLP-1 may additionally protect against the neurological consequences of hyperglycaemia. In turn, this could potentially lead to improved outcomes in acute stroke and neurodegeneration with several studies showing a correlation between stress hyperglycaemia and functional outcome, morbidity and mortality [96]. Furthermore, it has recently been hypothesised that GLP-1 agonists could lower blood glucose levels without the risk of hypoglycaemia in critically ill patients, thereby minimising the occurrence of treatment-related morbidity [97].

By further elucidating the molecular mechanisms responsible for the beneficial effects of GLP-1R activation in the brain, it may be possible to harness the neuroprotective properties of GLP-1 for the targeted treatment of ischaemic stroke and neurodegenerative disease. Moreover, clinical trials are currently underway where GLP-1 analogues are being utilised as anti-obesity therapies, due to their potent effects on satiety and food intake [98-101]. As such, GLP-1 could soon be added to our armamentarium as a therapeutic target above and beyond its usefulness as a glucose-regulating agent in type 2 diabetes.

\section{References}

1. Drucker DJ (2006) The biology of incretin hormones. Cell Metab 3: 153-165.

2. Burcelin R, Serino M, Cabou C (2009) A role for the gut-to-brain GLP-1dependent axis in the control of metabolism. Curr Opin Pharmacol 9: 744-752.

3. Baggio LL, Drucker DJ (2007) Biology of incretins: GLP-1 and GIP. Gastroenterology; 132: 2131-2157.

4. Dhanvantari S, Seidah NG, Brubaker PL (1996) Role of prohormone convertases in the tissue-specific processing of proglucagon. Mol Endocrinol 10: 342-355.

5. Brubaker PL, Drucker DJ (2004) Minireview: Glucagon-like peptides regulate cell proliferation and apoptosis in the pancreas, gut, and central nervous system. Endocrinology 145: 2653-2659.

6. Yusta B, Baggio LL, Estall JL, Koehler JA, Holland DP, et al. (2006) GLP-1 receptor activation improves beta cell function and survival following induction of endoplasmic reticulum stress. Cell Metab 4: 391-406.

7. Drucker DJ, Nauck MA (2006) The incretin system: glucagon-like peptide- 1 receptor agonists and dipeptidyl peptidase- 4 inhibitors in type 2 diabetes. Lancet 368: 1696-1705.

8. Meloni AR, DeYoung MB, Lowe C, Parkes DG (2013) GLP-1 receptor activated insulin secretion from pancreatic $\hat{\mathrm{I}}^{2}$-cells: mechanism and glucose dependence. Diabetes Obes Metab 15: 15-27.

9. Holst JJ (2007) The physiology of glucagon-like peptide 1. Physiol Rev 87: 1409-1439.

10. Alvarez E, Martínez MD, Roncero I, Chowen JA, García-Cuartero B, et al. (2005) The expression of GLP-1 receptor mRNA and protein allows the effect of GLP-1 on glucose metabolism in the human hypothalamus and brainstem. J Neurochem 92: 798-806.

11. Larsen PJ, Holst JJ (2005) Glucagon-related peptide 1 (GLP-1): hormone and neurotransmitter. Regul Pept 128: 97-107.

12. Trapp S, Richards JE (2013) The gut hormone glucagon-like peptide-1 produced in brain: is this physiologically relevant? Curr Opin Pharmacol 13: 964-969.
13. Kappe C, Tracy LM, Patrone C, Iverfeldt K, Sjöholm ^̊ (2012) GLP-1 secretion by microglial cells and decreased CNS expression in obesity. J Neuroinflammation 9: 276.

14. Kastin AJ, Akerstrom V, Pan W (2002) Interactions of glucagon-like peptide-1 (GLP-1) with the blood-brain barrier. J Mol Neurosci 18: 7-14.

15. Rodriquez de Fonseca F, Navarro M, Alvarez E, Roncero I, Chowen JA, et al. (2000) Peripheral versus central effects of glucagon-like peptide-1 receptor agonists on satiety and body weight loss in Zucker obese rats. Metabolism 49: 709-717.

16. Burcelin R, Cani PD, Knauf C (2007) Glucagon-like peptide-1 and energy homeostasis. J Nutr 137: 2534S-2538S.

17. Näslund E, Hellström PM (2007) Appetite signaling: from gut peptides and enteric nerves to brain. Physiol Behav 92: 256-262.

18. Dailey MJ, Moran TH (2013) Glucagon-like peptide 1 and appetite. Trends Endocrinol Metab 24: 85-91.

19. Vrang N, Hansen M, Larsen PJ, Tang-Christensen M (2007) Characterization of brainstem preproglucagon projections to the paraventricular and dorsomedial hypothalamic nuclei. Brain research 1149: 118-126.

20. Näslund E, Gutniak M, Skogar S, Rössner S, Hellström PM (1998) Glucagon-like peptide 1 increases the period of postprandial satiety and slows gastric emptying in obese men. Am J Clin Nutr 68: 525-530.

21. Imery $\tilde{A} 1 / 4 \mathrm{Z} N$, YeÄŸen BC, Bozkurt A, Co̊̊Ÿkun T, Villanueva-Pe $\tilde{A}$ \pm acarrillo ML, et al. (1997) Glucagon-like peptide-1 inhibits gastric emptying via vagal afferent-mediated central mechanisms. Am J Physiol 273: G920-927.

22. Nakabayashi H, Nishizawa M, Nakagawa A, Takeda R, Niijima A (1996) Vagal hepatopancreatic reflex effect evoked by intraportal appearance of tGLP-1. Am J Physiol 271: E808-813.

23. Plamboeck A, Veedfald S, Deacon CF, Hartmann B, Wettergren A, et al. (2013) The effect of exogenous GLP-1 on food intake is lost in male truncally vagotomized subjects with pyloroplasty. Am J Physiol Gastrointest Liver Physiol 304: G1117-1127.

24. Hayes MR, Leichner TM, Zhao S, Lee GS, Chowansky A, et al. (2011) Intracellular signals mediating the food intake-suppressive effects of hindbrain glucagon-like peptide-1 receptor activation. Cell Metab 13: 320-330.

25. Schick RR, Zimmermann JP, vorm Walde T, Schusdziarra V (2003) Peptides that regulate food intake: glucagon-like peptide 1-(7-36) amide acts at lateral and medial hypothalamic sites to suppress feeding in rats. American journal of physiology Regulatory, integrative and comparative physiology; 284: R1 427-435.

26. Turton MD, O'Shea D, Gunn I, Beak SA, Edwards CM, et al. (1996) A role for glucagon-like peptide-1 in the central regulation of feeding. Nature 379: 69-72.

27. Dalvi PS, Nazarians-Armavil A, Purser MJ, Belsham DD (2012) Glucagon-like peptide-1 receptor agonist, exendin-4, regulates feedingassociated neuropeptides in hypothalamic neurons in vivo and in vitro. Endocrinology; 153: 2208-22.

28. Sisley S, Gutierrez-Aguilar R, Scott M, Alessio DA, Sandoval DA, et al. (2014) Neuronal GLP1R mediates liraglutide's anorectic but not glucoselowering effect. J Clin Invest 124: 2456-2463.

29. Hayes MR, De Jonghe BC, Kanoski SE (2010) Role of the glucagon-likepeptide-1 receptor in the control of energy balance. Physiology \& behavior; 100: 503-510.

30. Hayes MR (2012) Neuronal and intracellular signaling pathways mediating GLP-1 energy balance and glycemic effects. Physiol Behav 106: 413-416.

31. Shirazi R, Palsdottir V, Collander J, Anesten F, Vogel H, et al. (2013) Glucagon-like peptide 1 receptor induced suppression of food intake, and body weight is mediated by central IL-1 and IL-6. Proc Natl Acad Sci U S A 110: 16199-16204.

32. Naslund E, Barkeling B, King N (1999) Energy intake and appetite are suppressed by glucagon-like peptide-1 (GLP-1) in obese men. 
International journal of obesity and related metabolic disorders: journal of the International Association for the Study of Obesity 23: 304-311.

33. Gutzwiller JP, Drewe J, Göke B, Schmidt H, Rohrer B, et al. (1999) Glucagon-like peptide-1 promotes satiety and reduces food intake in patients with diabetes mellitus type 2. Am J Physiol 276: R1541-1544.

34. Verdich C, Flint A, Gutzwiller JP, Näslund E, Beglinger C, et al. (2001) A meta-analysis of the effect of glucagon-like peptide-1 (7-36) amide on ad libitum energy intake in humans. J Clin Endocrinol Metab 86: 4382-4389.

35. De Silva A, Salem V, Long CJ, Makwana A, Newbould RD, et al. (2011) The gut hormones PYY 3-36 and GLP-1 7-36 amide reduce food intake and modulate brain activity in appetite centers in humans. Cell Metab 14: 700-706.

36. Schlogl H, Kabisch S, Horstmann A (2013) Exenatide-induced reduction in energy intake is associated with increase in hypothalamic connectivity. Diabetes care; 36: 1933-1940.

37. Wadden TA, Hollander P, Klein S, Niswender K, Woo V, et al. (2013) Weight maintenance and additional weight loss with liraglutide after low-calorie-diet-induced weight loss: the SCALE Maintenance randomized study. Int J Obes (Lond) 37: 1443-1451.

38. Kelly AS, Rudser KD, Nathan BM, Fox CK, Metzig AM, et al. (2013) The effect of glucagon-like peptide-1 receptor agonist therapy on body mass index in adolescents with severe obesity: a randomized, placebocontrolled, clinical trial. JAMA Pediatr 167: 355-360.

39. (2013) Treatment of Antipsychotic-associated Obesity With a GLP-1 Analogue (TAO).

40. Gejl M, Egefjord L, Lerche S (2012) Glucagon-like peptide-1 decreases intracerebral glucose content by activating hexokinase and changing glucose clearance during hyperglycemia. Journal of cerebral blood flow and metabolism: official journal of the International Society of Cerebral Blood Flow and Metabolism 32: 2146-2152.

41. Lerche S, Brock B, Rungby J, Bøtker HE, Møller N, et al. (2008) Glucagon-like peptide-1 inhibits blood-brain glucose transfer in humans. Diabetes 57: 325-331.

42. Gejl M, Lerche S, Egefjord L, Brock B, Møller N, et al. (2013) Glucagonlike peptide-1 (GLP-1) raises blood-brain glucose transfer capacity and hexokinase activity in human brain. Front Neuroenergetics $5: 2$.

43. Knauf C, Cani PD, Perrin C (2005) Brain glucagon-like peptide-1 increases insulin secretion and muscle insulin resistance to favor hepatic glycogen storage. The Journal of clinical investigation 115: 3554-3563.

44. Sandoval DA, Bagnol D, Woods SC, D'Alessio DA, Seeley RJ (2008) Arcuate glucagon-like peptide 1 receptors regulate glucose homeostasis but not food intake. Diabetes 57: 2046-2054.

45. Sandoval D (2008) CNS GLP-1 regulation of peripheral glucose homeostasis. Physiol Behav 94: 670-674.

46. Lockie SH, Heppner KM, Chaudhary N, Chabenne JR, Morgan DA, et al. (2012) Direct control of brown adipose tissue thermogenesis by central nervous system glucagon-like peptide-1 receptor signaling. Diabetes 61: 2753-2762.

47. Degn KB, Juhl CB, Sturis J (2004) One week's treatment with the longacting glucagon-like peptide 1 derivative liraglutide (NN2211) markedly improves 24-h glycemia and alpha- and beta-cell function and reduces endogenous glucose release in patients with type 2 diabetes. Diabetes; 53: 1187-1194.

48. Cechin SR, Pérez-Álvarez I, Fenjves E, Molano RD, Pileggi A, et al. (2012) Anti-inflammatory properties of exenatide in human pancreatic islets. Cell Transplant 21: 633-648.

49. Krasner NM, Ido Y, Ruderman NB, Cacicedo JM (2014) Glucagon-like peptide-1 (GLP-1) analog liraglutide inhibits endothelial cell inflammation through a calcium and AMPK dependent mechanism. PLoS One 9: e97554.

50. Ceriello A, Novials A, Ortega E, Canivell S, La Sala L, et al. (2013) Glucagon-like peptide 1 reduces endothelial dysfunction, inflammation, and oxidative stress induced by both hyperglycemia and hypoglycemia in type 1 diabetes. Diabetes Care 36: 2346-2350.
51. Kodera R, Shikata K, Kataoka HU (2011). Glucagon-like peptide-1 receptor agonist ameliorates renal injury through its anti-inflammatory action without lowering blood glucose level in a rat model of type 1 diabetes. Diabetologia; 54: 965-978.

52. Velmurugan K, Bouchard R, Mahaffey G, Pugazhenthi S (2012) Neuroprotective actions of glucagon-like peptide-1 in differentiated human neuroprogenitor cells. J Neurochem 123: 919-931.

53. Perry T, Haughey NJ, Mattson MP, Egan JM, Greig NH (2002) Protection and reversal of excitotoxic neuronal damage by glucagon-like peptide-1 and exendin-4. J Pharmacol Exp Ther 302: 881-888.

54. Holst JJ, Burcelin R, Nathanson E (2011) Neuroprotective properties of GLP-1: theoretical and practical applications. Curr Med Res Opin 27: 547-558.

55. Liu WJ, Jin HY, Lee KA, Xie SH, Baek HS, et al. (2011) Neuroprotective effect of the glucagon-like peptide-1 receptor agonist, synthetic exendin-4, in streptozotocin-induced diabetic rats. Br J Pharmacol 164: 1410-1420.

56. Li Y, Tweedie D, Mattson MP, Holloway HW, Greig NH (2010) Enhancing the GLP-1 receptor signaling pathway leads to proliferation and neuroprotection in human neuroblastoma cells. J Neurochem 113: 1621-1631.

57. Iwai T, Ito S, Tanimitsu K, Udagawa S, Oka J (2006) Glucagon-like peptide-1 inhibits LPS-induced IL-1beta production in cultured rat astrocytes. Neurosci Res 55: 352-360.

58. Sharma MK, Jalewa J, Hölscher C (2014) Neuroprotective and antiapoptotic effects of liraglutide on SH-SY5Y cells exposed to methylglyoxal stress. J Neurochem 128: 459-471.

59. Hou J, Manaenko A, Hakon J, Hansen-Schwartz J, Tang J, et al. (2012) Liraglutide, a long-acting GLP-1 mimetic, and its metabolite attenuate inflammation after intracerebral hemorrhage. Journal of cerebral blood flow and metabolism: official journal of the International Society of Cerebral Blood Flow and Metabolism 32: 2201-2210.

60. Parthsarathy V, Hölscher C (2013) The type 2 diabetes drug liraglutide reduces chronic inflammation induced by irradiation in the mouse brain. Eur J Pharmacol 700: 42-50.

61. McClean PL, Parthsarathy V, Faivre E, Hölscher C (2011) The diabetes drug liraglutide prevents degenerative processes in a mouse model of Alzheimer's disease. J Neurosci 31: 6587-6594.

62. Rachmany L, Tweedie D, Li Y, Rubovitch V, Holloway HW, et al. (2013) Exendin-4 induced glucagon-like peptide-1 receptor activation reverses behavioral impairments of mild traumatic brain injury in mice. Age (Dordr) 35: 1621-1636.

63. Hölscher C (2014) Central effects of GLP-1: new opportunities for treatments of neurodegenerative diseases. J Endocrinol 221: T31-41.

64. Plummer MP, Meier JJ, Deane AM (2013) The gut-brain axis in the critically ill: is glucagon-like peptide-1 protective in neurocritical care? Crit Care 17: 163.

65. Lindsberg PJ, Roine RO (2004) Hyperglycemia in acute stroke. Stroke 35: 363-364.

66. Baird TA, Parsons MW, Phanh T (2003) Persistent poststroke hyperglycemia is independently associated with infarct expansion and worse clinical outcome. Stroke; a journal of cerebral circulation; 34: 2208-2214.

67. Darsalia V, Mansouri S, Ortsäter H, Olverling A, Nozadze N, et al. (2012) Glucagon-like peptide-1 receptor activation reduces ischaemic brain damage following stroke in Type 2 diabetic rats. Clin Sci (Lond) 122: 473-483.

68. Darsalia V, Ortsäter H, Olverling A, Darlöf E, Wolbert P, et al. (2013) The DPP-4 inhibitor linagliptin counteracts stroke in the normal and diabetic mouse brain: a comparison with glimepiride. Diabetes 62: 1289-1296.

69. Daly SC, Chemmanam T, Loh PS, Gilligan A, Dear AE, et al. (2013) Exenatide in acute ischemic stroke. Int J Stroke 8: E44.

70. Hsu PF, Sung SH, Cheng HM, Yeh JS, Liu WL, et al. (2013) Association of clinical symptomatic hypoglycemia with cardiovascular events and 
total mortality in type 2 diabetes: a nationwide population-based study. Diabetes Care 36: 894-900.

71. Li Y, Perry T, Kindy MS (2009). GLP-1 receptor stimulation preserves primary cortical and dopaminergic neurons in cellular and rodent models of stroke and Parkinsonism. Proceedings of the National Academy of Sciences of the United States of America; 106: 1285-1290.

72. Teramoto S, Miyamoto N, Yatomi K (2011). Exendin-4, a glucagon-like peptide-1 receptor agonist, provides neuroprotection in mice transient focal cerebral ischemia. Journal of cerebral blood flow and metabolism: official journal of the International Society of Cerebral Blood Flow and Metabolism; 31: 1696-1705.

73. Briyal S, Gulati K, Gulati A (2012) Repeated administration of exendin-4 reduces focal cerebral ischemia-induced infarction in rats. Brain Res 1427: 23-34.

74. Sato K, Kameda M, Yasuhara T, Agari T, Baba T, et al. (2013) Neuroprotective effects of liraglutide for stroke model of rats. Int J Mol Sci 14: 21513-21524.

75. Lee CH, Yan B, Yoo KY (2011). Ischemia-induced changes in glucagonlike peptide-1 receptor and neuroprotective effect of its agonist, exendin-4, in experimental transient cerebral ischemia. Journal of neuroscience research; 89: 1103-1113.

76. Read PA, Hoole SP, White PA (2011). A pilot study to assess whether glucagon-like peptide-1 protects the heart from ischemic dysfunction and attenuates stunning after coronary balloon occlusion in humans. Circulation Cardiovascular interventions; 4: 266-272.

77. Nikolaidis LA, Mankad S, Sokos GG, Miske G, Shah A, et al. (2004) Effects of glucagon-like peptide- 1 in patients with acute myocardial infarction and left ventricular dysfunction after successful reperfusion. Circulation 109: 962-965.

78. Lønborg J, Vejlstrup N, Kelbæk H, Bøtker HE, Kim WY, et al. (2012) Exenatide reduces reperfusion injury in patients with ST-segment elevation myocardial infarction. Eur Heart J 33: 1491-1499.

79. Best JH, Lavillotti K, DeYoung MB, Garrison LP (2012). The effects of exenatide bid on metabolic control, medication use and hospitalization in patients with type 2 diabetes mellitus in clinical practice: a systematic review. Diabetes, obesity \& metabolism; 14: 387-398.

80. Ott A, Stolk RP, van Harskamp F, Pols HA, Hofman A, et al. (1999) Diabetes mellitus and the risk of dementia: The Rotterdam Study. Neurology 53: 1937-1942.

81. Biessels GJ, Staekenborg S, Brunner E, Brayne C, Scheltens P (2006) Risk of dementia in diabetes mellitus: a systematic review. Lancet Neurol 5: 64-74.

82. Abbas T, Faivre E, Hölscher C (2009) Impairment of synaptic plasticity and memory formation in GLP-1 receptor KO mice: Interaction between type 2 diabetes and Alzheimer's disease. Behav Brain Res 205: 265-271.

83. During MJ, Cao L, Zuzga DS, Francis JS, Fitzsimons HL, et al. (2003) Glucagon-like peptide-1 receptor is involved in learning and neuroprotection. Nat Med 9: 1173-1179.

84. Parthsarathy V, Hölscher C (2013) Chronic treatment with the GLP1 analogue liraglutide increases cell proliferation and differentiation into neurons in an AD mouse model. PLoS One 8: e58784.

85. Han WN, Hölscher C, Yuan L, Yang W, Wang XH, et al. (2013) Liraglutide protects against amyloid- $\mathrm{I}^{2}$ protein-induced impairment of spatial learning and memory in rats. Neurobiol Aging 34: 576-588.
86. Harkavyi A, Abuirmeileh A, Lever R, Kingsbury AE, Biggs CS, Whitton PS (2008). Glucagon-like peptide 1 receptor stimulation reverses key deficits in distinct rodent models of Parkinson's disease. Journal of neuroinflammation; 5: 19.

87. Bertilsson G, Patrone C, Zachrisson O (2008). Peptide hormone exendin-4 stimulates subventricular zone neurogenesis in the adult rodent brain and induces recovery in an animal model of Parkinson's disease. Journal of neuroscience research; 86: 326-338.

88. Martin B, Golden E, Carlson OD, Pistell P, Zhou J, et al. (2009) Exendin-4 improves glycemic control, ameliorates brain and pancreatic pathologies, and extends survival in a mouse model of Huntington's disease. Diabetes 58: 318-328.

89. Hölscher C (2012) Potential role of glucagon-like peptide-1 (GLP-1) in neuroprotection. CNS Drugs 26: 871-882.

90. Olmos IA, Dickson J, Kefalopoulou Z, Djamshidian A, Ell P, et al. (2013) Exenatide and the treatment of patients with Parkinson's disease. J Clin Invest 123: 2730-2736.

91. (2013) GLP-1 for the Treatment of Stroke Patients With Space-occupying Intracerebral Hemorrhage.

92. Evaluating Liraglutide in Alzheimer's Disease (ELAD)

93. McIntyre RS, Powell AM, Beilin OK, et al.(2013) The role of GLP-1 analogues in reducing reperfusion injury after acute stroke in patients with impaired swallowing. The neuroprotective effects of GLP-1: possible treatments for cognitive deficits in individuals with mood disorders. Behavioural brain research; 237: 164-171.

94. Lockie SH (2013) Glucagon-like peptide-1 receptor in the brain: role in neuroendocrine control of energy metabolism and treatment target for obesity. J Neuroendocrinol 25: 597-604.

95. Capes SE, Hunt D, Malmberg K, Pathak P, Gerstein HC (2001) Stress hyperglycemia and prognosis of stroke in nondiabetic and diabetic patients: a systematic overview. Stroke 32: 2426-2432.

96. Schwartz S, DeFronzo RA (2013) Is incretin-based therapy ready for the care of hospitalized patients with type 2 diabetes?: The time has come for GLP-1 receptor agonists! Diabetes Care 36: 2107-2111.

97. Effect of Liraglutide on Body Weight in Non-diabetic Obese Subjects or Overweight Subjects With Co-morbidities: Obesity and Pre-diabetes.

98. The Effects of Exenatide (Byetta ) on Energy Expenditure and Weight Loss in Nondiabetic Obese Subjects.

99. Isacson R, Nielsen E, Dannaeus K, Bertilsson G, Patrone C, et al. (2011) The glucagon-like peptide 1 receptor agonist exendin-4 improves reference memory performance and decreases immobility in the forced swim test. Eur J Pharmacol 650: 249-255.

100. Ma T, Du X, Pick JE, Sui G, Brownlee M, et al. (2012) Glucagon-like peptide-1 cleavage product GLP-1 (9-36) amide rescues synaptic plasticity and memory deficits in Alzheimer's disease model mice. J Neurosci 32: 13701-13708.

101. Kimura R, Okouchi M, Fujioka H, Ichiyanagi A, Ryuge F, et al. (2009) Glucagon-like peptide-1 (GLP-1) protects against methylglyoxal-induced PC12 cell apoptosis through the PI3K/Akt/mTOR/GCLc/redox signaling pathway. Neuroscience 162: 1212-1219. 